\title{
Recurrent haemorrhage from iatrogenic left ventricular aneurysm
}

\author{
S. R. PANDAY, G. B. PAR U L K A R, \\ M. D. KELKAR, AND P.K. SEN \\ From the Department of Surgery, K.E.M. Hospital, Parel, Bombay 12
}

Most of the literature on penetrating wounds of the heart is concerned with the diagnosis and management of acute cardiac tamponade, but very scant attention seems to have been paid to its sequelae and complications. Cardiac aneurysm is now increasingly being recognized as a complication following accidental wounds, incisions into the heart for introducing instruments, and openheart correction of certain cardiac defects.

In this communication a report of a case of traumatic ventricular aneurysm following accidental incision into the left ventricle is presented, because of the unusual circumstances that led to its production and its mode of presentation.

\section{CASE REPORT}

B. R., a boy aged 10 years, was admitted to the K.E.M. Hospital, Bombay, on 4 February 1963 for reduction under general anaesthesia of a slipped epiphysis of the lower end of the right radius. During induction of anaesthesia with ethyl chloride the child developed cardiac arrest. Immediate closed cardiac massage was attempted for about one and a half minutes without any favourable response. The child was intubated, and the chest was opened through the fourth left intercostal space. While opening the chest in haste there was an accidental injury to the pericardium and left ventricular myocardium. The incised wound in the myocardium was about $1 \frac{1}{4}$ in. (31.75 $\mathrm{mm}$.) long, but the actual opening into the left ventricular cavity was 0.5 in. $(12.7 \mathrm{~mm}$.) long. There was considerable loss of blood into the pericardial and pleural cavities. Open cardiac massage for about two and a half minutes was followed by spontaneous restoration of normal cardiac rhythm. The left ventricular wound was sutured with interrupted black silk sutures. Blood loss was replaced; the pericardium was sutured and the chest was closed in layers with an underwater seal drain in the left pleural cavity.

Post-operatively the patient maintained a blood pressure of about $100 / 70 \mathrm{~mm}$. Hg. His electrocardiogram at this time showed a slight myocardial injury pattern. On the third post-operative day the air entry on the left side was found to be diminished, the temperature was raised (oral temperature $102^{\circ} \mathrm{F}$.), and the pulse rate was 140 per minute. The pyrexia continued in spite of antibiotics and other measures. A radiograph of the chest taken on 12 February 1963 revealed extensive haziness over the left base (Fig. 1). On 13 February the left chest was re-explored to evacuate the blood clots and to re-expand the collapsed left lung.

During this operation a patch of softening about $1.5 \mathrm{~cm}$. in diameter was detected over the front of the left ventricle. This area was carefully covered with a pericardial flap (Fig. 2) and the chest was closed in layers with a drain.

On the eighth post-operative day the sutures were removed. The wound had healed well, except anteriorly, where an area of reddening and a tense pulsatile bulge $3 \mathrm{~cm}$. in diameter had appeared. A diagnosis of empyema necessitans was made. Aspiration of the swelling at this stage yielded only a small quantity of dark-coloured blood.

On 10 March there was a spontaneous haemorrhage from the wound. A radiograph of the chest showed a vague opacity just outside the apex of the heart and partly overlying it. Bleeding was controlled by external pressure and the blood loss was replaced. Two days later there was another episode of severe haemorrhage from the same wound. Blood loss was again replaced and re-exploration of the wound was planned.

The chest was opened through the fourth left intercostal space after excising the previous operation scar. There was a false left ventricular aneurysm 2 by $1 \mathrm{~cm}$. which had ruptured (Fig. 3). Bleeding from the ruptured aneurysm was controlled by finger pressure, and a Bailey's myocardial clamp was applied over the base of the aneurysm. A part of the necrotic wall of the aneurysm was excised. Four interrupted silk sutures were used to close the opening in the left ventricle. A patch of fascia lata was then sutured over the area to strengthen the suture line (Fig. 4). The chest was closed in layers with a drain. Postoperatively there was full lung expansion and the blood pressure was maintained at about $100 / 70 \mathrm{~mm}$. Hg. The wound healed well except for a small length anteriorly. 


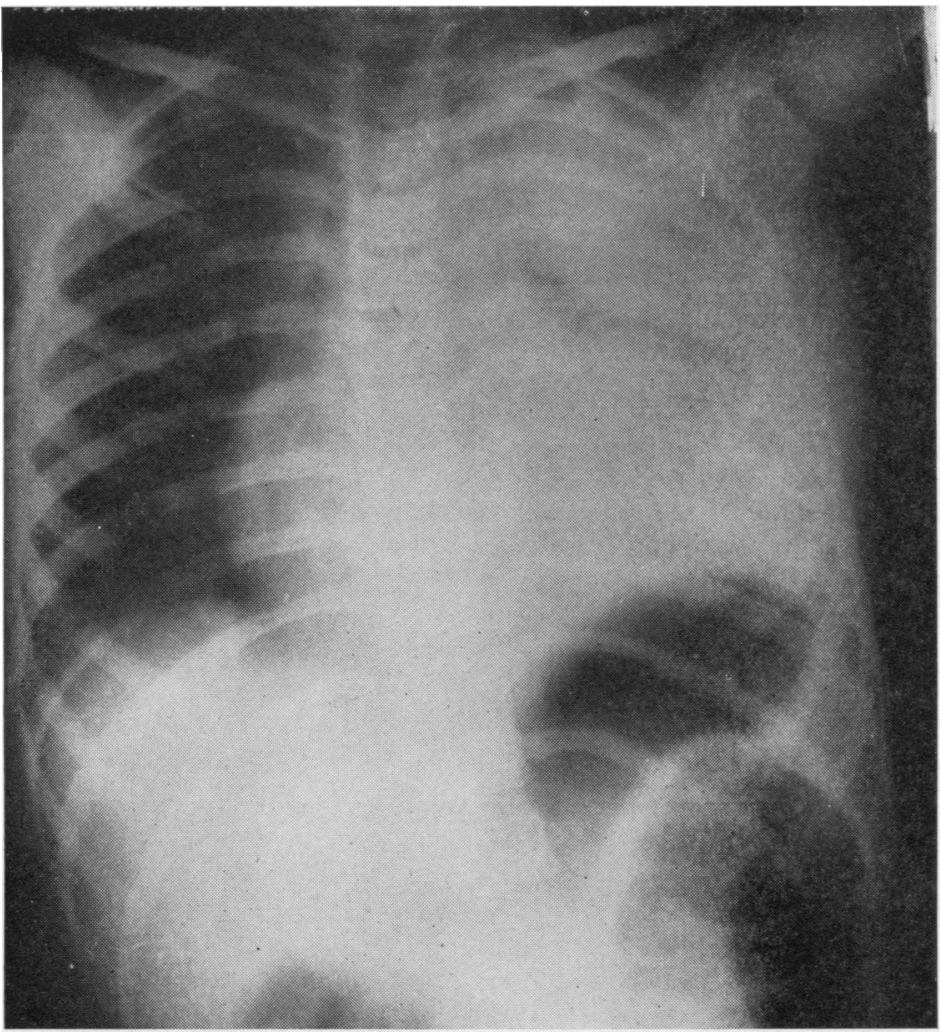

FIG. 1. Chest radiograph showing extensive haziness on the left side. On exploration the left pleural cavity was found to be full of blood clot and the left lung was almost completely collapsed.

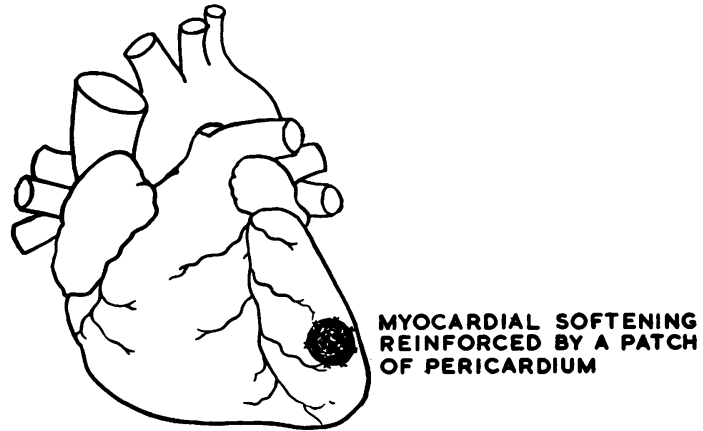

FIG. 2

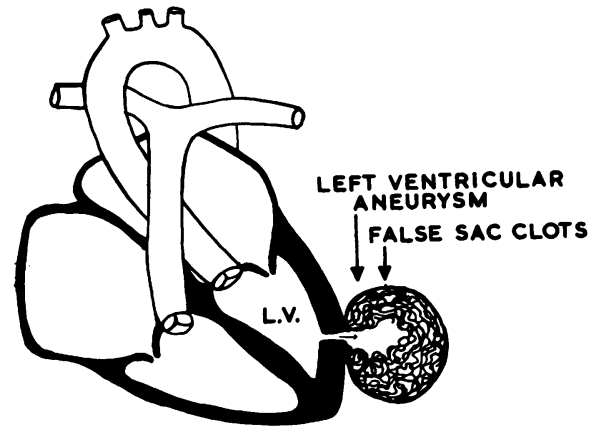

FIG. 3

FIG. 2. Illustrates an area of myocardial softening which was reinforced by a patch of pericardium (first operation).

FIG. 3. Shows the left ventricular aneurysm, partially filled with blood clot, and surrounded by a false sac formed from adjacent tissue. The aneurysm was communicating with the left ventricular cavity. 


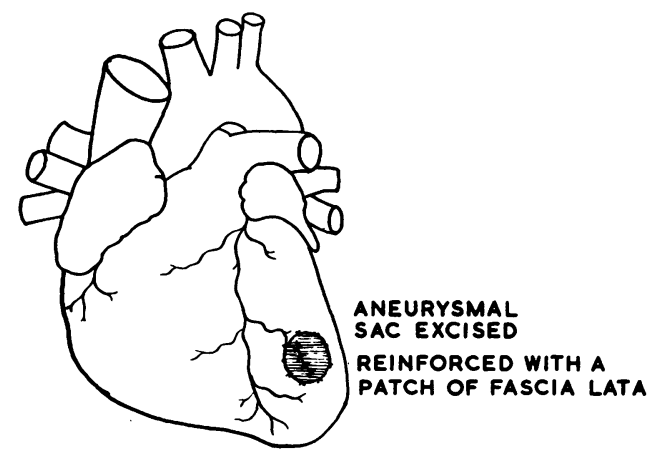

FIG. 4. Illustrates the use of a patch of fascia lata to reinforce the myocardium at the site of the ventricular aneurysm after the aneurysmal sac had been excised (second operation).

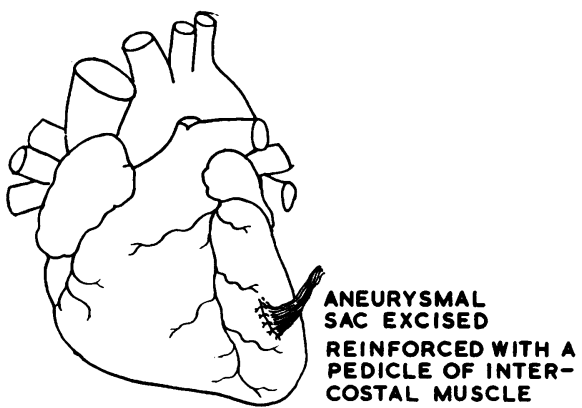

FIG. 6. Illustrates the technique of reinforcement of the 윽 myocardium with a pedicle of intercostal muscle bundle after excision of the left ventricular aneurysm (final operation).

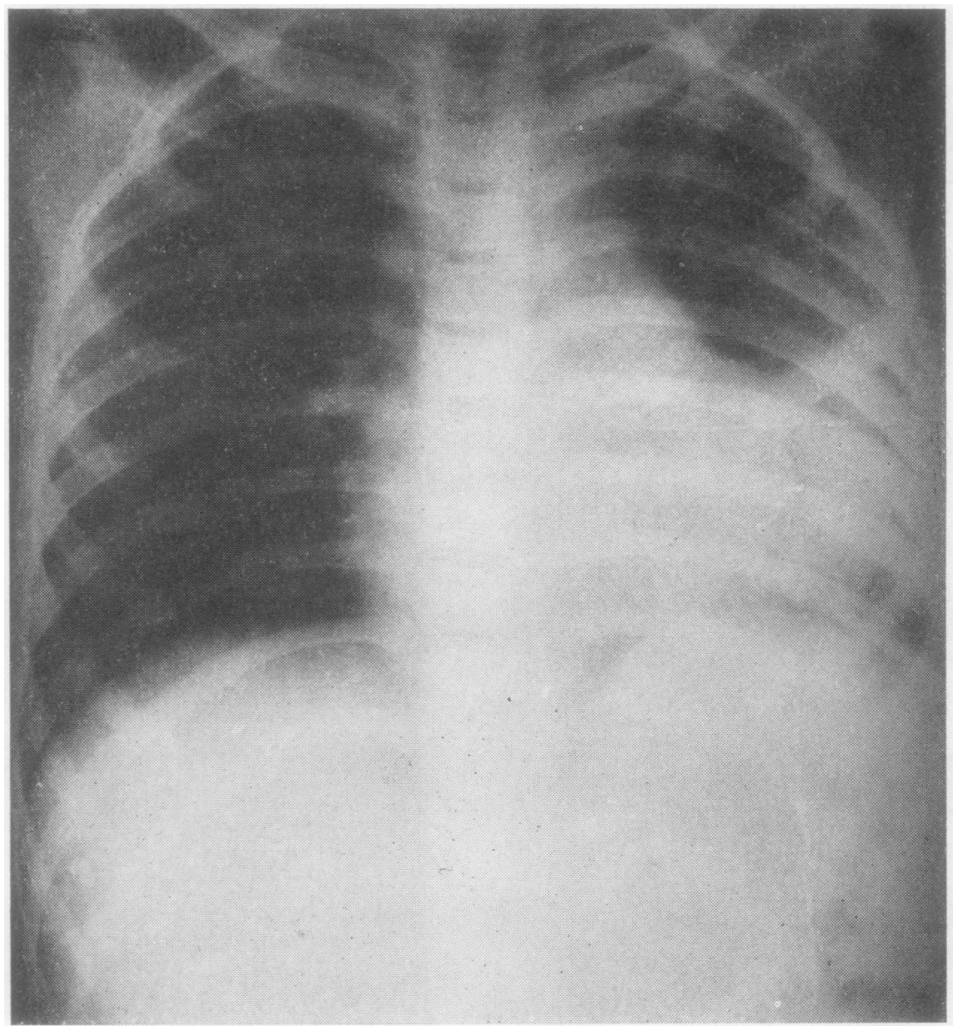

FIG. 5. Radiograph of the chest showing an opacity on the left side just outside the cardiac silhouette and partly overlying it. 
Three weeks later the patient again developed a praecordial bulge in the region of the apex of the heart. Radiographs of the chest showed an opacity (Fig. 5) on the left side of the heart. Fluoroscopy showed that the opacity was paradoxically pulsatile. An electrocardiogram showed changes of anterolateral infarction.

On 25 April the patient complained of pain on the left side of the chest and had a severe bout of coughing, after which there was a further severe bleeding from the wound. This was controlled by external pressure, and the blood loss was replaced. The patient was moved to the theatre.

A left thoracotomy was again carried out, this time through the fifth rib bed. On opening the chest it was noticed that the previous fascia lata graft was thinned out, and a new false aneurysmal sac had developed over the left ventricle, which had ruptured. Bleeding was controlled with finger pressure, and a Bailey's myocardial clamp was applied over the site of bleeding. The false sac was excised and clots were evacuated. Interrupted silk sutures were applied over the myocardium to stop the bleeding. A muscle graft from the intercostal muscle was then sutured over the softened area of the myocardium (Fig. 6). The chest was closed in layers, and a drain was left in the pleural cavity.

Recovery was uneventful. There was no further bleeding. There was no bulge over the praecordium, expansion of the lungs was full, there was no pyrexia, and the wound healed well.

On 20 June 1963 the patient was discharged from the hospital after a total stay of four and a half months, during which period he had undergone thoracotomy four times for recurrent haemorrhages from recurrent left ventricular aneurysms.

One month after discharge from the hospital the patient was asymptomatic. There was no praecordial bulge and the wound had healed well. Examination of the heart did not reveal any abnormality. Radiographs of the chest showed full expansion of the lungs and an E.C.G. was within normal limits.

Six months later, when last seen, the patient was asymptomatic, and investigations showed no abnormality (Fig. 7). The E.C.G. was normal.

\section{REVIEW OF THE LITERATURE}

Aneurysms of the heart resulting from myocardial infarction are not uncommon, but aneurysms

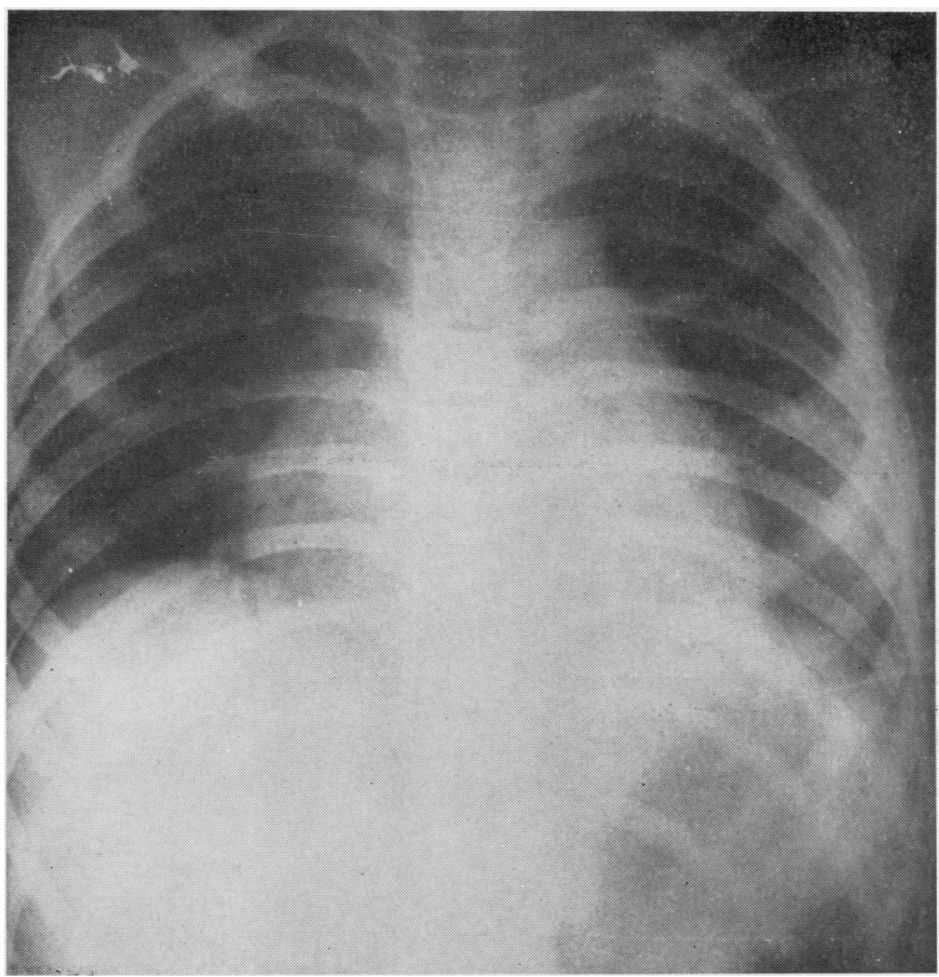

FIG. 7. Chest radiograph (taken six months after the last operation) shows fully expanded lungs and an almost normal cardiac silhouette. 
resulting from trauma and surgical incisions are said to be rare. A ventricular aneurysm due to coronary occlusion was first described by Hunter in 1757. Sternberg (1914) was the first to appreciate the concept of chronic ventricular aneurysm and described the first case occurring during life.

The usual site of post-infarction aneurysm has been the left ventricle. These aneurysms develop as a result of scar formation, which replaces the necrotic post-infarctional myocardium.

Cardiac aneurysm has aroused little interest. There was no mention of this condition in Harken's (1946) report concerning the late removal of 56 missiles from the heart, though it is stated that the only fragment that involved the left ventricle was found in a small cystic myocardial hernia.

Lyons and Perkins in 1958 reported a partially calcified aneurysm of the left ventricle that was detected on plain radiographs taken 12 years after the suturing of a stab wound which had penetrated the left ventricle.

Smith, Goldberg, and Bailey (1957) described another left ventricular aneurysm that followed a surgical accident. In trying to split the lateral commissure of the mitral valve the surgeon's finger perforated the left ventricle from within. The laceration was repaired, but an aneurysm developed at the site within three months.

Aneurysms after ventriculotomy are also uncommon on the left side of the heart. Two cases were reported by Segel, Fatti, Adler, and Crawshaw (1957) following aortic valvotomy.

In 1957 Smith et al. described a false aneurysm that occurred in a woman who had aortic stenosis. Valvotomy was done by the transventricular route. Eighteen months later she developed a left ventricular aneurysm which was successfully resected.

A post-operative aneurysm of the right ventricle, though not incisional, was described in 1955 by McCord and Blount. Seven weeks after infundibular resection for a Fallot's tetralogy a pulsating swelling was observed in the praecordium. At a subsequent operation a large, thinwalled true aneurysm of the infundibular chamber was found.

Derra and Loogen (1959) reported a true aneurysm of the right ventricle. This occurred six years after a pulmonary valvotomy by Brock's closed method. This aneurysm was 'the size of an apple' and it was resected.

AETIOLOGY There is more than one factor that ultimately decides the formation of a traumatic ventricular aneurysm. The heart muscle does no? regenerate after a wound and heals by scar. The process of healing was studied in dogs by Thomas? and Ziffren in 1952, and their findings were confirmed in 1958 by Warren, Muller, East, an\& Sosa. The findings are summarized below.

A zone of necrosis within the suture line was a constant feature. In cases of wound rupture itw was found that the suture had produced consider able necrosis. In those wounds that did not break down granulation tissue rapidly invaded the necrotic muscle, completely replacing it in twós or three weeks to produce a scar that at first was? as thick as the wall of the ventricles. When the length of the incision was limited to $2 \mathrm{~cm}$ ? attenuation of the scar did not occur to any great extent, but with wounds 3 to $4 \mathrm{~cm}$. long, whicho had not divided any of the coronary vessels $\varsigma^{-}$ broadening and thinning of the scar began withing a month and progressed until the scar measured half or less of its original thickness. This process was most marked at the apex.

Beck (1944) tried and failed to produce ai aneurysm in dogs by localized crushing of the myocardium and ligation of the coronary artery

Infection of the suture line has been though to be one of the causes of the development of ventricular aneurysms.

Lyons and Perkins (1958), who reported two cases of ventricular aneurysm, attributed them no? to infection but to faults in suturing.

Bailey, Bolton, Nichols, and Gilman (1958) regard most, if not all, traumatic aneurysms as false, and believe that the fault lies in a failuren to place the sutures through the full thickness of muscle, thereby facilitating dissection. One stitch tied badly or too tightly may cause excessive necrosis and subsequent disruption of that part of the wound; the breakdown is early, but thes aneurysm to which it gives rise may occur much later.

It has been presumed that traumatic aneurysmsof the ventricle are characteristically falses aneurysms, but this view has been challenged byN Kerr, Wilcken, and Steiner (1961) and by Smithy心 Boone, and Stallworth (1950).

Since true aneurysms follow infarction in patients with coronary heart disease, it is suggestec by Kerr et al. (1961) that infarction precedes? traumatic aneurysms.

Intraventricular pressure is another factor tha is responsible for the production of both true and false aneurysms. The rate of growth in a traumati aneurysm is fairly rapid, though subsequent en음 largement may be slow. 
EXPERIMENTAL Tyson, Mandelbaum, and Shumacker (1962) studied experimentally the haemodynamic effects of artificially constructed left ventricular aneurysms on left ventricular function. They concluded that patent, paradoxically pulsating, left ventricular aneurysms depressed left ventricular function curves when the aneurysms were either acute or chronic. An increase in the left ventricular diameter alone, caused by the presence of patent, non-pulsating left ventricular aneurysms or a left ventricular patch graft, did not alter left ventricular function curves.

Austen, Tsunekawa, Bender, Ebert, and Morrow (1962) also studied experimentally the effects of left ventricular aneurysms. Aneurysms of various sizes were constructed by suturing urinary bladders of donor animals to the ventricle and creating a communication between this sac and the ventricular cavity. Effective left ventricular function was depressed and cardiac output and the mean aortic pressure fell in proportion to the size of the aneurysm. All parameters returned to near control level when the aneurysm was occluded.

In the case presented, the aetiology of the ventricular aneurysm could be attributed mainly to two factors. First, because the accidental ventricular wound complicated cardiac arrest, its suturing was done rapidly and hence was likely to have been insecure or inadequate. Secondly, as aseptic precautions were not taken during cardiac massage, the ventricular wound and pleural cavity were infected, as was evident from the subsequent course of the case.

TYPES OF VENTRICULAR ANEURYSMS Kerr et al. (1961) have divided ventricular aneurysms into two groups, true and false.

A true ventricular aneurysm is a part of the heart. A saccular aneurysm with a narrow neck develops from a small area of weakness in the myocardium. If the area affected is larger, a widenecked sac will develop, and sooner or later the wall of the sac will be replaced by fibrous tissue.

On the other hand, a false aneurysm lies outside the heart and communicates with it through a perforation in the heart muscle. This develops as a result of a persistent leak of blood from the ventricle. Fibrous adhesions develop from the surrounding structures and from tough fibrous tissue which is indistinguishable from the wall of a true aneurysm, even on histological examination.

In the present case the ventricular aneurysm was a false one, since the sac was composed of fibrous tissue and pleuropericardial adhesions. Although there was a communication with the ventricular cavity, there was no myocardial tissue in the wall forming the sac of the aneurysm on histopathological examination.

\section{DIAGNOSIS}

Clinical In many cases cardiac aneurysms present no clinical signs, and even if present they are rarely diagnostic. Abnormal cardiac pulsations; increased cardiac borders, and signs of left ventricular failure may occur.

Radiological and electrocardiographic Electrocardiography and radiology are the mainstay in the diagnosis of ventricular aneurysms.

Goldberger and Schwartz (1948) have reported that the E.C.G. tracings are characteristic of ventricular aneurysms. They believed that the upward QRS complex in lead aVR was pathognomonic of ventricular aneurysm. They considered that the absence of this pattern in the right arm lead in a case of myocardial infarction indicated the absence of a ventricular aneurysm.

Radiology provides the only reliable means of diagnosing cardiac aneurysms. A left ventricular aneurysm, true or false, appears on radiographs as a circumscribed projection beyond the normal cardiac silhouette. In the lateral film it appears as a separate rounded or oval shadow, partly or wholly superimposed on that of the heart.

Systolic expansion observed on fluoroscopy or on a permanent record obtained on cineradiography is good evidence in favour of an aneurysm, but it will not be seen if the aneurysmal sac is full of clots.

TREATMENT Surgical treatment of an aneurysm of the left ventricle was attempted by Beck in 1944. In his case he incised the pericardium around the aneurysm, leaving the pericardial patch adherent to the lesion. A fascia lata graft was then sutured to the adherent pericardium, and plication sutures were taken centrally to reduce the size of the aneurysm.

There are two ways of treating ventricular aneurysms-by external reinforcement and by resection with ventriculoplasty.

Techniques similar to Beck's have been applied in 24 patients using omentum, skin, intercostal muscle, pectoralis major muscle, and diaphragm (Lillehei, Levy, DeWall, and Warden, 1962) to support the aneurysmal wall, to prevent its further 
expansion, and in the hope of stimulating development of collateral circulation into the ischaemic fibrotic sac.

Bailey et al. in 1958 reported six cases of ventricular aneurysm treated surgically with excision and ventriculoplasty; there were five survivors. Likoff and Bailey (1955) stated that the method of tangential excision with a special clamp was a simple and effective method, and the 'flush out' technique controlled embolism from mural thrombi. In their opinion the use of cardiopulmonary bypass was not justified in these cases.

Chapman, Amad, and Cooley (1961) reported 14 cases of post-infarction aneurysm which were surgically excised (using a pump oxygenator), with three operative deaths.

Lillehei et al. in 1962 also reported five cases of post-infarction left ventricular aneurysm. Their method of excision with ventriculoplasty was carried out under cardiopulmonary bypass in all five cases without mortality.

In our case, because the aneurysm happened to have a very thin-walled sac, it ruptured repeatedly, presenting as a surgical emergency on each occasion.

During the third operation the aneurysmal sac, which was thin and necrotic, was excised. The myocardial clamp of Bailey et al. (1958) was used for haemostasis. The ventricular wound was sutured and reinforced with a fascia lata patch graft over it. Beck in 1944 had used fascia lata as a means of external reinforcement for ventricular aneurysm without excising the aneurysmal sac.

About six weeks after the ventriculoplasty our patient had another episode of bleeding, when the previous ventriculoplasty gave way and a new aneurysmal sac formed and ruptured. During the final successful operation the newly formed aneurysmal sac was excised; the ventricular wall was resutured, and this time intercostal muscle was used to reinforce the sutured ventricular wound. A subsequent search of the literature revealed that Spacek (1956) also used intercostal muscle for external reinforcement of the ventricular aneurysm with a gratifying result.
SUMMARY

A case of traumatic left ventricular false aneurysm that developed at the site of an accidental incision over the left ventricle during open cardiac massage is reported.

The pathogenesis of ventricular aneurysm following trauma is discussed.

The clinical features, investigations, and management of ventricular aneurysm are outlined.

\section{REFERENCES}

Austen, W. G., Tsunekawa, T., Bender, H. W., Ebert, P. A., and Morrow, A. G. (1962). Acute hemodynamic effects of left ventricular aneurysm-an experimental study in dogs. J. surg. Res., 2,161 .

Bailey, C. P., Bolton, H. E., Nichols, H., and Gilman, R. A. (1958). Ventriculoplasty for cardiac aneurysm. J. thorac. Surg., 35, 37. Beck, C. S. (1944). Operation for aneurysm of the heart. Ann. Surg., 120, 34.

Chapman, D. W., Amad, K., and Cooley, D. A. (1961). Ventricular aneurysm. Fourteen cases subjected to cardiac bypass repair using the pump oxygenator. Amer. J. Cardiol., 8, 633.

Derra, E., and Loogen, F. (1959). Utber Herzkammeraneurysmen $\vec{c}$ bzw. Herzkammerdivertikel und ihre operative Behandlung. o Dtsch. med. Wschr., 84, 1585 .

Goldberger, E., and Schwartz, S. P. (1948). Electrocardiographic patterns of ventricular aneurysm. Amer. J. Med., 4, 243.

Harken, D. E. (1946). Foreign bodies in, and in relation to, the thoracic blood vessels and heart. Surg. Gynec. Obstet., 83, 117.

Hunter, J. (1757). An Account of the Dissection of Morbid Bodys. Original manuscript in the library of Royal College of Surgeons, Original manuscript in the library of Royal College of Surgeons, London. Section 32, p. 30

Kerr, W. F., Wilcken, D. E. L., and Steiner, R. E. (1961). Incisional aneurysms of the left ventricle. Brit. Heart J., $23,88$.

Likoff, W., and Bailey, C. P. (1955). Ventriculoplasty: excision of myocardial aneurysm. $J$. Amer med. Ass. 158, 915 .

Lillehei, C. W., Levy, M. J., DeWall, R. A., and Warden, H. E. (1962). Resection of myocardial aneurysms after infarction during temporary cardiopulmonary bypass. Circulation, 26, 206.

Lyons, C., and Perkins, R. (1958). Resection of a left ventricular aneurysm secondary to cardiac stab wound. Ann. Surg., 147, 256.

McCord, M. C., and Blount, S. G. (1955). Complications following infundibular resection in Fallot's tetralogy. Circulation, 11, 754 .

Segel. N., Fatti, L., Adler, D., and Crawshaw, G. R. (1957). Aortic stenosis. An evaluation of results of surgery in 20 cases. $S$. Afr. med. $J, 31,899$.

Smith, R. C., Goldberg, H., and Bailey, C. P. (1957). Pseudoaneurysm ס of the left ventricle: diagnosis by direct cardioangiography. 3 Surgery, 42, 496.

Smithy, H. G., Boone, J. A., and Stallworth, J. M. (1950). Surgical treatment of constrictive valvular disease of the heart. Surg. Gynec. Obstet., 90, 175.

Spacek, B. (1956). Surgical treatment of chronic post-infarction aneurysm. Klin. Med. (Mosk.), 37, no. 9, p. 30

Sternberg, M. (1914). Das chronische partielle Herzaneurysma. Franz Deuticke, Vienna and Leipzig. Thomas, C. G., and Ziffren, S. E. (1952). Healing of extensive cardiac 을.

Tyson, K., Mandelbaum, I., and Shumacker, H. B. (1962). Experi- $\mathrm{N}$ mental production and study of left ventricular aneurysms. $J$. thorac. cardiovasc. Surg., 44, 731 .

Warren, W. D., Muller, W. H., East, M.. and Sosa, O. (1958). N Experimental study of the anatomic and physiologic effects of $N$ incisions into the left ventricle. Surg. Forlim, 9, 257. 